\title{
A prospective randomized study to compare dexmedetomidine and dexamethasone as an adjunct to bupivacaine in transversus abdominis plane block for post-operative analgesia in caesarean delivery
}

\author{
Jitender Thakur ${ }^{1}$, Bharti Gupta ${ }^{1 *}$, Amit Gupta ${ }^{2}$, Ravinder Kumar Verma ${ }^{1}$, \\ Anita Verma ${ }^{1}$, Payal Shah ${ }^{3}$
}

\begin{abstract}
${ }^{1}$ Department of Anesthesia, DRPGMC, Tanda (Kangra), Himachal Pradesh, India
${ }^{2}$ Department Obstetrics and Gynecology, DRPGMC, Tanda (Kangra), Himachal Pradesh, India

${ }^{3}$ Department Anesthesia, Zonal Hospital, Dharamsala (Kangra), Himachal Pradesh, India
\end{abstract}

Received: 23 August 2019

Revised: 08 November 2019

Accepted: 13 November 2019

\author{
*Correspondence: \\ Dr. Bharti Gupta, \\ E-mail: drbharti203@gmail.com
}

Copyright: (c) the author(s), publisher and licensee Medip Academy. This is an open-access article distributed under the terms of the Creative Commons Attribution Non-Commercial License, which permits unrestricted non-commercial use, distribution, and reproduction in any medium, provided the original work is properly cited.

\begin{abstract}
Background: Caesarean section is most frequently performed surgery worldwide. Patients experience moderate to severe pain in the first 48 hours post-operatively. Aim of this study was to evaluate the efficacy of dexmedetomidine and dexamethasone as an adjunct to bupivacaine in ultrasound guided TAP block for postoperative analgesia in patients of caesarean section.

Methods: A total 120 ASA I and II patients undergoing elective and emergency caesarean section under subarachnoid block were randomly divided into three groups $\mathrm{B}, \mathrm{BDM}, \mathrm{BDX}$ to receive bupivacaine alone or dexmedetomidine or dexamethasone as an adjunct to bupivacaine in ultrasound guided TAP block. Postoperatively, the patients were evaluated for pain level at rest and on movement with a $10 \mathrm{~cm}$ visual analog scale (VAS) pain score $(0=$ no pain and $10=$ worst pain $)$, time to demand of first analgesic request, number of analgesic requirements, nausea or vomiting, sedation and patient satisfaction at 0 hours and at 2, 4, 6, 12, 18, and 24 hours.

Results: VAS score was significantly higher in group B in comparison to BDM and BDX, and higher in BDX in comparison to group BDM. Mean duration of analgesia was significantly higher in group BDM in comparison to group B and BDX. Total number of rescue analgesic demands were significantly lower in group BDM in comparison to group B and BDX. Sedation score and satisfaction score was higher in group BDM as compared to group B and BDX.

Conclusions: Addition of dexmedetomidine and dexamethasone as an adjunct to bupivacaine reduces postoperative pain, prolongs analgesia, decreases demand for additional analgesics and provides better maternal satisfaction as compared to plain bupivacaine group in TAP block in patients undergoing caesarean section under subarachnoid block. Among dexmedetomidine and dexamethasone, dexmedetomidine had prolonged analgesia as compared to dexamethasone group.
\end{abstract}

Keywords: Caesarean section, Dexmedetomidine, Dexamethasone, Postoperative pain, Transversus abdominis plane block 


\section{INTRODUCTION}

Caesarean section is often associated with severe pain, which may result in patient dissatisfaction, impaired patient rehabilitation and prolonged hospitalization..$^{1,2}$ Therefore, a well-planned analgesia regimen is required to ensure adequate maternal satisfaction, early initiation of breast feeding and early mobilization to prevent risk of thrombo-embolism as a result of immobility due to pain. Pain after caesarean section is mainly contributed to somatic component of pain (Abdominal wall incision) and less because of visceral pain (uterus). Thereby requiring a multimodal approach for postoperative pain management in the form of NSAIDS, opioids, local infiltration by LA and neuraxial blocks in the form of epidurals. $^{3}$

Transversus abdominis plane block is used to provide analgesia to the anterior and lateral abdominal wall. A local anaesthetic solution (Bupivacaine) is injected into facial plane between the internal oblique and transversus abdominis muscle under ultrasound guidance. The procedural simplicity of this block, along with the reliable level of analgesia (T6-L1) and longer duration and quality of analgesia makes TAP block a good option for lower abdominal gynaecological surgeries, as also been reported by American society of regional anaesthesia (ASRA). ${ }^{4}$

Some of the adjuncts which have been used so far in literature in TAP block are dexamethasone, magnesium and $\alpha 2$ agonists. Out of these agonists, $\alpha 2$ agonist drugs and Dexamethasone are most commonly used drugs, owing to their analgesic potential and safety profile. ${ }^{5}$

A comparative study between dexmedetomidine versus dexamethasone as an adjuvant to bupivacaine in ultrasound guided TAP block for postoperative analgesia in patients undergoing caesarean section under subarachnoid block was planned. Our primary aim was to compare the dexmedetomidine and dexamethasone as an adjunct to bupivacaine post-operatively up to 24 hours for duration of analgesia and demand of additional analgesics. Secondary aims were to assess sedation, nausea, vomiting, haemodynamic stability and maternal satisfaction in relation with the early start of breast feeding and early ambulation.

\section{METHODS}

The study was approved by institutional ethical committee and was carried over a period of one year from March 2018 to February 2019. 120 ASA I-II patients, scheduled for emergency and elective caesarean section under subarachnoid block were included in the study and one patient was excluded due to block failure. Patient's refusal for block, local infection at the site of TAP block and allergy to study drugs were the exclusion criteria.
It was a prospective, double blind randomized control study. The patients were allocated to one of the three groups by random number chart. Random number was enclosed in a sealed opaque envelope and opened by one of the investigators to know the study drug to be administered. The operating surgeon and observer anesthesiologist who collected the postoperative data were blinded to the study drug. The study drug solution was prepared and given to the investigator by a nonparticipant staff.

The group B received $38 \mathrm{ml}$ of $0.25 \%$ bupivacaine and 2 $\mathrm{ml}$ of $0.9 \% \mathrm{NS}$ to make total volume of $40 \mathrm{ml}$, group BDM-38 ml of $0.25 \%$ bupivacaine and $2 \mathrm{ml}$ of $1 \mu \mathrm{g} / \mathrm{kg}$ dexmedetomidine and group BDX-38 ml of $0.25 \%$ bupivacaine and $2 \mathrm{ml}$ of $0.1 \mathrm{mg} / \mathrm{kg}$ dexamethasone.

All patients undergoing caesarean section were given subarachnoid block in lateral position and surgery was started after confirmation of T6 level. Postoperatively, after regression of sensory block to T10 dermatome.

A USG guided TAP block was given using linear probe (6-13 MHz) in all groups with respective drug solutions. $23 \mathrm{G}$ spinal needle was advanced by ultrasound guided in plane technique at the anterior axillary line between the $12^{\text {th }}$ rib and iliac crest with umbilicus at the center and exact location of the needle tip in a plane between internal oblique muscle, transverse abdominis muscle was identified with $1 \mathrm{ml}$ of normal saline. ${ }^{6,7}$

After confirmation of hypo echoic area on USG imaging, the injection of $20 \mathrm{ml}$ of drug solution was given. The amount of $20 \mathrm{ml}$ was also injected on the opposite side using the identical technique). Postoperatively, the patients were evaluated in post-anaesthesia care unit (time 0 hours) and at 2, 4, 6, 12, 18, and 24 hours by an investigator blinded to group assignment. Pain level (somatic and visceral) at rest and on movement (knee flexion) was quantified with a $10 \mathrm{~cm}$ visual analog scale (VAS) pain score $(0=$ no pain and $10=$ worst pain $)$, time to demand of first tramadol request, number of supplemental analgesics. For the first 24 hours, the protocol for postoperative analgesia in our institute consisted of injection diclofenac intramuscular 8 hourly and injection tramadol $50 \mathrm{mg}$ intravenous on demand if pain scores remain high $(\mathrm{VAS}>4)$.

Nausea and vomiting were assessed on a four-point scale (None- 1, Mild -2, Moderate- 3, Severe- 4). Injection Ondansetron $4 \mathrm{mg}$ IV was given if score was more than 2.

Level of sedation was assessed as a sedation score of 0-3, where $0=$ awake and alert, $1=$ quietly awake, $2=$ asleep but easily arousable, 3 = deep sleep, responding to painful stimulus. Patients were labeled to be sedated if score was $>2$. 
The patients were also interviewed after 24 hours of surgery regarding satisfaction with their pain management and comfort in view of early ambulation and early start of breast feeding on a 3-point scale (highly satisfied-1, satisfied-2, dissatisfied-3). In addition, haemodynamic monitoring (systolic blood pressure, diastolic blood pressure and heart rate) was also done at similar study points.

\section{Statistical analysis}

Data was presented as frequency, mean, and standard deviation whenever applicable. Categorical variables between 2 groups were compared using Chi square test of
Fischer exact test. One-way ANOVA followed by posthoc analysis (Bonferroni) was used to compare quantitative variables between 3 groups. $\mathrm{P}$ value $<0.05$ was considered significant. Statistical analysis was performed using SPSS v21.

\section{RESULTS}

A total of 119 patients were enrolled into the study and randomized into 3 groups - group B, BDM, and BDX.

Patient characteristics like age, weight and ASA status were comparable in all three groups (Table 1).

Table 1: Comparison between three groups according to demographic variables.

\begin{tabular}{|lllll|}
\hline Parameter & Group B, N = 39 & Group BDM, $\mathbf{N}=40$ & Group BDX, $\mathbf{N}=40$ & P value \\
\hline Age (years) & $28.59 \pm 3.59$ & $27.62 \pm 3.50$ & $27.50 \pm 3.42$ & $0.324^{\#}$ \\
\hline Weight (kg) & $64.59 \pm 7.50$ & $63.97 \pm 7.33$ & $64.72 \pm 7.73$ & $0.893^{\#}$ \\
\hline
\end{tabular}

Data presented as mean $\pm \mathrm{SD}$; \#One-way ANOVA.

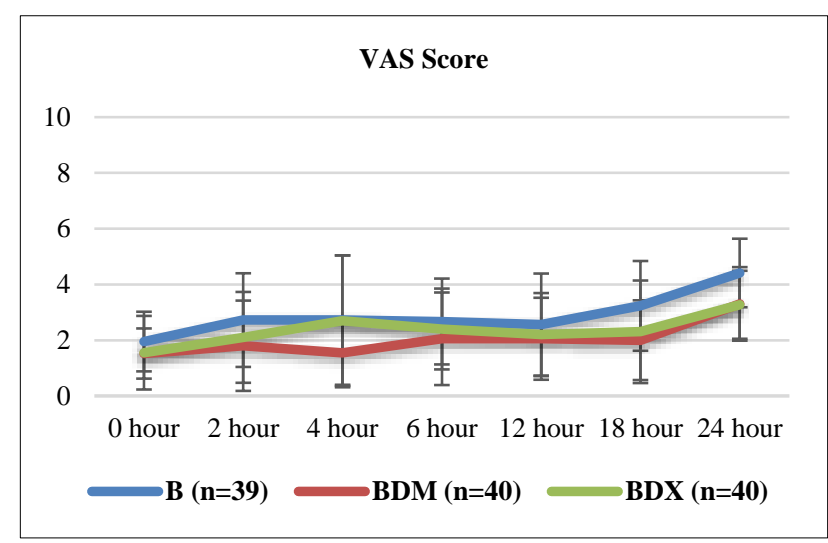

Figure 1: Comparison of VAS scores.

The VAS for pain was comparable in group B, BDM and BDX at 0 hour but at 4-hour, VAS score was significantly lower in group BDM in comparison to group $\mathrm{B}(\mathrm{P}=0.037)$ and group BDX (0.040). At 6 and 12 hours. VAS of the patients was comparable in group B, BDM, and BDX. Again at 18-hour, VAS of the patients was significantly higher in group $\mathrm{B}$ in comparison to group BDM $(\mathrm{P}=0.0003)$ and group $\mathrm{BDX}(\mathrm{P}=0.039)$. At 24 hour, VAS of the patients in group $\mathrm{B}$ was significantly higher than VAS of the patients in group BDM ( $\mathrm{P}<$ $0.0001)$ and BDX $(\mathrm{P}<0.0001)$. So, VAS score was significantly higher in group B at 2-hour, 4-hour, 18hour, and 24-hour in comparison to BDM and BDX and higher in BDX in comparison to group BDM (Figure 1).

Mean duration of analgesia (time to first rescue analgesia) was significantly higher in group BDM
$(407.99 \pm 4.60)$ minutes in comparison to group B $(178.99 \pm 5.00)$ and group BDX $(325.88 \pm 5.51)$ (Figure 2).

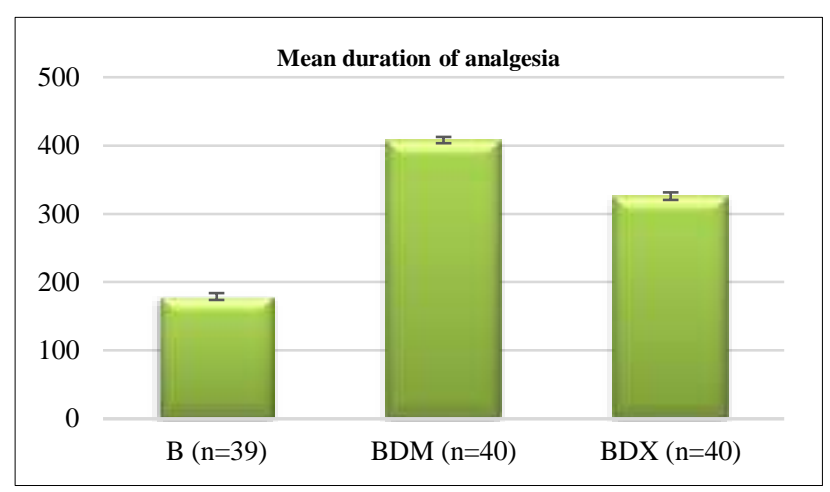

Figure 2: Comparison of mean duration of analgesia (minutes).

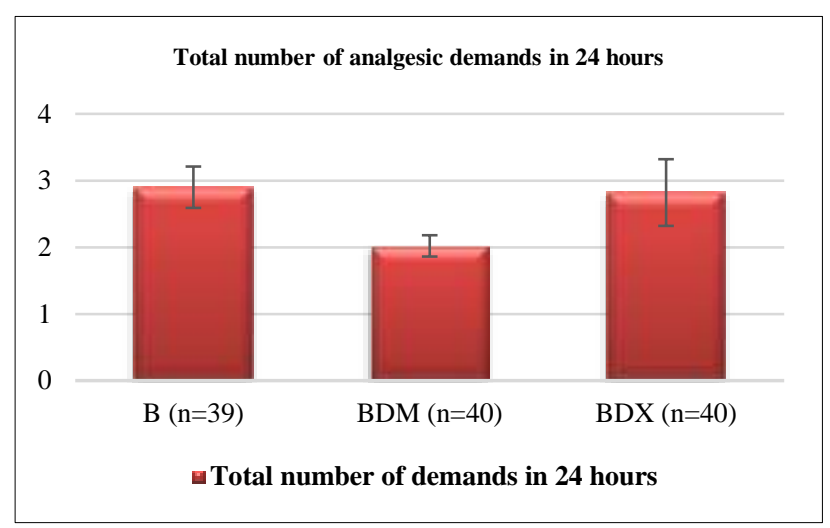

Figure 3: Total number of analgesic demands. 


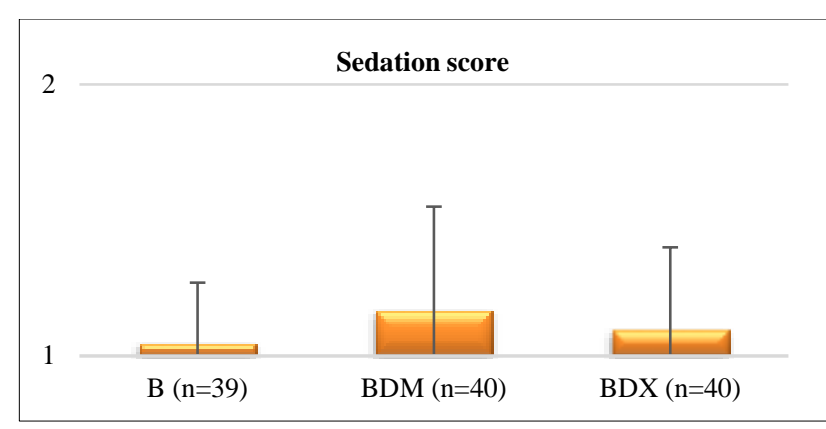

Figure 4: Comparison of sedation score.
Total number of rescue analgesic demand in 24 hours was significantly lower in group BDM (2.02 \pm 0.16$)$ in comparison to group B $(2.90 \pm 0.31)$ and group BDX $(2.82 \pm 0.50)$ (Figure 3).

The PONV scores were similar in all groups. Sedation score and satisfaction score was marginally higher in group BDM which was not significant (Figure 4).

Heart rate was comparable between group $\mathrm{B}$, group BDM, and group BDX at all study points except at 2 hours when it was lower in group BDM (Table 2).

Table 2: Comparison of heart rate among different groups.

\begin{tabular}{|llllll|}
\hline Heart rate & $\mathrm{B}(\mathrm{n}=39)$ & $\mathrm{BDM}(\mathrm{n}=40)$ & $\mathrm{BDX}(\mathrm{n}=40)$ & ANOVA Statistic & Post-hoc analysis \\
\hline 0-hour & $86.97 \pm 10.27$ & $87.00 \pm 10.15$ & $87.35 \pm 7.47$ & 0.980 & - \\
\hline 2-hour & $83.49 \pm 9.80$ & $76.35 \pm 6.76$ & $83.25 \pm 9.87$ & $<0.001$ & $\begin{array}{l}\text { B versus BDM }=0.0002 ; \mathrm{B} \\
\text { versus BDX }=1.000 ; \\
\end{array}$ \\
& & & & versus BDX $=0.002$ \\
\hline 4-hour & $77.38 \pm 7.46$ & $77.30 \pm 7.38$ & $79.45 \pm 5.99$ & 0.300 & - \\
\hline 6-hour & $79.49 \pm 8.44$ & $79.75 \pm 8.34$ & $81.10 \pm 6.47$ & 0.681 & - \\
\hline 12-hour & $78.61 \pm 8.13$ & $78.75 \pm 8.07$ & $79.40 \pm 5.98$ & 0.882 & - \\
\hline 18-hour & $79.84 \pm 8.29$ & $79.60 \pm 8.33$ & $81.95 \pm 7.12$ & 0.351 & - \\
\hline 24-hour & $80.26 \pm 8.84$ & $80.20 \pm 8.73$ & $81.50 \pm 5.95$ & 0.712 & - \\
\hline
\end{tabular}

Data presented as mean \pm SD; One-way ANOVA followed by Bonferroni Post-hoc.

Table 3: Comparison of diastolic blood pressure in different groups.

\begin{tabular}{|c|c|c|c|c|c|}
\hline Diastolic BP & $B(n=39)$ & BDM $(n=40)$ & BDX $(n=40)$ & ANOVA statistics & Post-hoc analysis \\
\hline 0 -hour & $73.69 \pm 5.16$ & $71.05 \pm 5.06$ & $68.95 \pm 5.32$ & $<0.0001$ & $\begin{array}{l}\mathrm{B} \text { versus } \mathrm{BDM}=0.076 ; \mathrm{B} \text { versus } \mathrm{BDX}= \\
<0.0001 ; \mathrm{BDM} \text { versus } \mathrm{BDX}=0.218\end{array}$ \\
\hline 2-hour & $74.26 \pm 5.15$ & $70.65 \pm 4.56$ & $70.55 \pm 4.75$ & 0.001 & $\begin{array}{l}\mathrm{B} \text { versus } \mathrm{BDM}=0.004 ; \mathrm{B} \text { versus } \mathrm{BDX}= \\
0.003 ; \mathrm{BDM} \text { versus } \mathrm{BDX}=1.000\end{array}$ \\
\hline 4-hour & $75.18 \pm 5.59$ & $69.65 \pm 5.41$ & $71.00 \pm 4.73$ & $<0.0001$ & $\begin{array}{l}\mathrm{B} \text { versus } \mathrm{BDM}<0.0001 ; \mathrm{B} \text { versus } \mathrm{BDX} \\
=0.002 ; \mathrm{BDM} \text { versus } \mathrm{BDX}=0.759\end{array}$ \\
\hline 6-hour & $73.23 \pm 7.06$ & $71.05 \pm 4.96$ & $69.90 \pm 5.74$ & 0.046 & $\begin{array}{l}\mathrm{B} \text { versus } \mathrm{BDM}=0.323 ; \mathrm{B} \text { versus } \mathrm{BDX}= \\
0.044 ; \mathrm{BDM} \text { versus } \mathrm{BDX}=1.000\end{array}$ \\
\hline 12-hour & $76.82 \pm 4.44$ & $70.80 \pm 5.18$ & $70.65 \pm 5.84$ & $<0.0001$ & $\begin{array}{l}\mathrm{B} \text { versus } \mathrm{BDM}<0.0001 ; \mathrm{B} \text { versus } \mathrm{BDX} \\
<0.0001 ; \mathrm{BDM} \text { versus } \mathrm{BDX}=1.000\end{array}$ \\
\hline 18-hour & $76.46 \pm 4.93$ & $70.10 \pm 5.45$ & $68.10 \pm 12.13$ & $<0.0001$ & $\begin{array}{l}\mathrm{B} \text { versus } \mathrm{BDM}=0.002 ; \mathrm{B} \text { versus } \mathrm{BDX}< \\
0.0001 ; \mathrm{BDM} \text { versus } \mathrm{BDX}=0.835\end{array}$ \\
\hline 24-hour & $75.95 \pm 5.51$ & $71.60 \pm 4.46$ & $70.45 \pm 5.39$ & $<0.0001$ & $\begin{array}{l}\mathrm{B} \text { versus } \mathrm{BDM}=0.001 ; \mathrm{B} \text { versus } \mathrm{BDX}< \\
0.0001 ; \mathrm{BDM} \text { versus } \mathrm{BDX}=0.958\end{array}$ \\
\hline
\end{tabular}

Data presented as mean \pm SD; \# (B vs. BDM); One-way ANOVA followed by Bonferroni Post-hoc.

Diastolic BP was significantly higher in group B in comparison to group BDX and group BDM up to 24 hours (Table 3).

\section{DISCUSSION}

The ideal analgesic regime should be efficacious without impacting the ability of mother to take care of the neonate and with minimal drug transfer through breast milk.
Limited availability of drugs, equipment cost and nonavailability of trained staff for monitoring are the major issues in providing adequate post caesarian section analgesia by epidurals.

The TAP block gives good analgesia, is cost affective, requires less expertise, and reduces consumption of opioids in post- operative period. 
This was observed by Srivastava U et al in their study which concluded that TAP block was effective in providing analgesia with a substantial reduction in tramadol use during $48 \mathrm{~h}$ after cesarean section when used as an adjunct to standard analgesia. ${ }^{8}$

For abdominal surgeries, TAP blocks have been demonstrated to decrease the use of postoperative opioids and their side effects such as sedation and PONV, increase the time to first request for further analgesia, provide more effective pain relief, earlier mobilization and faster recovery. ${ }^{9}$

Different local anaesthetics alone and addition of adjuvant to local anaesthesia may prolong the block's duration. A systematic review and meta-analysis of randomized controlled trials in 2015 by Zhang D and colleagues showed that addition of Dexamethasone to local anesthetics in ultrasound guided TAP block was a safe and effective strategy for postoperative analgesia in adult patients undergoing abdominal surgery. ${ }^{10}$

A systematic review for randomized controlled trials by Fusco P et al, that assessed the efficacy of ultrasound (US) guided TAP block following cesarean delivery and concluded that controversy surrounds the utility of USguided TAP block in cesarean section, evidence suggests that when correctly executed as part of a multimodal analgesic regimen, TAP block may reduce postoperative opioid consumption and opioid-related side effects, improving postoperative pain control and patient satisfaction. $^{11}$

In our study we observed that duration of analgesia was significantly higher in patients who received bupivacaine along with dexmedetomidine in comparison to the patients who received bupivacaine alone or with dexamethasone. Similar results were observed by Almarkbi and Kaki, who studied the effect of addition of dexmedetomidine to bupivacaine to perform TAP block. ${ }^{12,13}$ They concluded that the addition of dexmedetomidine to bupivacaine in TAP block achieves better local anesthesia and provides better pain control post-operatively with lower heart rate from $60 \mathrm{~min}$ from block to 4 hours postoperatively. Similarly, analgesia period was significantly higher in the patients who received bupivacaine and dexamethasone as an adjunct in comparison to the patients who received bupivacaine alone. Similar results have been reported by Abdeelal and colleagues. $^{14}$ Among these two adjuncts dexmedetomidine provided longer analgesia and there was no previous research for similar comparison. Because of prolonged pain free period total number of rescue analgesic demands in 24 hours were significantly lower in group BDM in comparison to group B and group BDX.

Sharma et al, determined the effect of the addition of dexamethasone to $0.5 \%$ ropivacaine on post-operative analgesia in USG guided TAP block for inguinal hernia repair and concluded that addition of dexamaethasone to ropivacaine in USG guided TAP block significantly reduces post-operative analgesia and reduces analgesic consumption. ${ }^{15-17}$ Our study observed that addition of dexmedetomidine to bupivacaine provided more sedation; however, the difference was not significant. Our results also match with Aksu et al and Mishra et al who observed that sedation was non-significantly higher in the patients who received dexmedetomidine in addition to bupivacaine. ${ }^{18,19} \mathrm{We}$ found that the patients satisfaction was non significantly higher in the patients who received dexmedetomidine in addition to bupivacaine in comparison to other groups. Such findings have also been reported previously by Aksu et al and Mishra et al. ${ }^{18,19}$ We observed that heart rate, systolic and diastolic BP was better maintained in BDX except decrease in heart rate at 2 hours was for very short time, and it can be explained by bradycardia causing property of alpha 2 agonist. Bradycardia is one of reported endocrine effects of dexmedetomidine. Bradycardia may occur with ongoing therapy mediated by central $\alpha 2 \mathrm{~A}$ adrenergic receptors, causing decreased release of nor adrenaline from the sympathetic nervous system. ${ }^{20,21}$ Systolic BP was comparable in all the groups up to 24 hour while diastolic $\mathrm{BP}$ was significantly lower in group BDX in comparison to group B and BDM at all time points up to 24 hour which can be explained by effect of alpha 2 agonist for BDM group and comparatively higher pain scores in group B and group BDM. Incidence of post-operative nausea vomiting was equivalent in all groups. We found no significant difference in age, weight, ASA class and duration of surgery.

\section{CONCLUSION}

Dexmedetomidine and dexamethasone as an adjunct to bupivacaine in post-operative pain scores, prolongs the duration of analgesia, decreases demands for rescue analgesia, and provides better patient satisfaction with improved quality of block.

The analgesia is maximally prolonged with dexmedetomidine without any significant adverse effects.

\section{ACKNOWLEDGMENTS}

Authors would like to thank all the patients who participated in study.

Funding: No funding sources

Conflict of interest: None declared

Ethical approval: The study was approved by the Institutional Ethics Committee

\section{REFERENCES}

1. Leung AY. Postoperative pain management in obstetric anesthesia - New challenges and solutions. J Clin Anesth. 2004;16:57-65. 
2. Gadsden J, Hart S, Santos AC. Post-cesarean delivery analgesia. Anesth Analg. 2005;101(5 Suppl):S62-9.

3. Urbanczae L. Transverse abdominis plane block. Anesth Intensive Ther. 2009;35:137-41.

4. Sharkey A, Borglum J, Blanco R, McDonnell J. TAP block: Past, present, and future. Am Soc Reg Anesth Pain Med. 2014;12:15-7.

5. Singh R, Kumar N, Jain A, Joy S. Addition of clonidine to bupivacaine in transversus abdominis plane block prolongs postoperative analgesia after cesarean section. J Anaesthesiol Clin Pharmacol. 2016;32(4):501-4.

6. Petersen P, Mathiesen O, Torup H, Dahl J. The transversus abdominis plane block: a valuable option for postoperative analgesia? A topical review. Acta Anaesthesiol Scand. 2010;54(5):529-35.

7. Baaj JM, Alsatli RA, Majaj HA, Babay ZA, Thallaj AK. Efficacy of ultrasound guided transversus abdominis plane (TAP) block for postcesarean section delivery analgesia: a double-blind, placebocontrolled, randomized study. Middle East $\mathrm{J}$ Anaesthesiol. 2010;20(6):821-6.

8. Srivastava U, Verma S, Singh TK, Gupta A, Saxsena A, Jagar KD. Efficacy of trans abdominis plane block for post cesarean delivery analgesia: A doubleblind, randomized trial. Saudi J Anesth. 2015;9(3):298-302.

9. Kim AJ, Yong RJ, Urman RD. The role of transversus abdominis plane blocks in enhanced recovery after surgery pathways for open and laparoscopic colorectal surgery. J Laparoendosc Adv Surg Tech. 2017;27(9):909-14.

10. Zhang D, Zhou C, Wei D, Ge L, Li Q. Dexamethasone added to local anesthetics in ultrasound-guided transversus abdominis plain (TAP) block for analgesia after abdominal surgery: A systematic review and meta-analysis of randomized controlled trials. PloS One. 2019;14(1):e0209646.

11. Fusco P, Scimia P, Paladini G, Fiorenzi M, Petrucci E, Pozone $\mathrm{T}$, et al. Transversus abdominis plane block for analgesia after Cesarean delivery. A systematic review. Minerva Anestesiol. 2015;81(2):195-204.

12. Almarakbi WA, Kaki AM. Addition of dexmedetomidine to bupivacaine in transversus abdominis plane block potentiates post-operative pain relief among abdominal hysterectomy patients: A prospective randomized controlled trial. Saudi J Anaesth. 2014;8(2):161-6.

13. Bansal P, Sood D. Effect of dexmedetomidine as an adjuvant to ropivacaine in ultrasound-guided transversus abdominis plane block for post-operative pain relief in cesarean section. J Obstet Anaesth Crit Care. 2018;8(2):79.

14. Abdelaal W, Metry A, Refaat M, Ragaei M, Nakhla G. Comparative Study between levobupivacine versus levobupivacaine plus dexmedetomidine for transversus abdominis plane block "TAP" in postoperative pain management after abdominoplasty. Enliven J Anesth Crit Care Med. 2015;2(2):4.

15. Sharma UD, Prateek, Tak H. Effect of addition of dexamethasone to ropivacaine on post-operative analgesia in ultrasonography-guided transversus abdominis plane block for inguinal hernia repair: A prospective, double-blind, randomised controlled trial. Indian J Anaesth. 2018;62(5):371-5.

16. Fouad HA, Mohammed A, Ahmed S, Mohammed Y, Osman M, Mohammed G, et al. Efficacy of preemptive dexamethasone added to bupivacaine in ultrasound guided transversus abdominus plain block for postoperative analgesia after inguinal herniorraphy. Am J Res Commun. 2016;4(5):27-42.

17. Falia MD, Kulkarni P. Comparison of dexamethasone and clonidine as an adjunct to bupivacaine in transversus abdominis plane block in patients undergoing lower segment caesarean section. Int J Res Med Sci. 2016;4(10):4481-6.

18. Aksu R, Patmano G, Biçer C, Emek E, Çoruh AE. Efficiency of bupivacaine and association with dexmedetomidine in transversus abdominis plane block ultrasound guided in postoperative pain of abdominal surgery. Brazilian J Anesthesiol. 2018;68(1):49-56.

19. Mishra M, Mishra S, Singh S. Ultrasound-guided transversus abdominis plane block: What are the benefits of adding dexmedetomidine to ropivacaine? Saudi Anaesth. 2017;11(1):58.

20. Venn RM, Bryant A, Hall GM, Grounds RM. Effects of dexmedetomidine on adrenocortical function, and the cardiovascular, endocrine and inflammatory responses in post-operative patients needing sedation in the intensive care unit. $\mathrm{Br} \mathrm{J}$ Anaesth. 2001;86(5):650-6.

21. Kaur M, Singh PM. Current role of dexmedetomidine in clinical anesthesia and intensive care. Anesth essays Res. 2011;5(2):128-33.

Cite this article as: Thakur J, Gupta B, Gupta A, Verma RK, Verma A, Shah P. A prospective randomized study to compare dexmedetomidine and dexamethasone as an adjunct to bupivacaine in transversus abdominis plane block for post-operative analgesia in caesarean delivery. Int J Reprod Contracept Obstet Gynecol 2019;8:4903-8. 